\section{Au@Pt dendrimer encapsulated nanoparticles as model electrocatalysts for comparison of experiment and theory $\dagger$}

\author{
David F. Yancey, ${ }^{a b c}$ Liang Zhang, ${ }^{a c d}$ Richard M. Crooks ${ }^{* a b c}$ and Graeme Henkelman*acd
}

Received 25th November 2011, Accepted 27th January 2012

DOI: $10.1039 / \mathrm{c} 2 \mathrm{sc00971d}$

In this paper we report the electrochemical synthesis of core@shell dendrimer-encapsulated nanoparticles (DENs) consisting of cores containing $147 \mathrm{Au}$ atoms $\left(\mathrm{Au}_{147}\right)$ and $\mathrm{Pt}$ shells having $\sim 54$ or $\sim 102$ atoms $\left(\mathrm{Au}_{147} @ \mathrm{Pt}_{n}(n=54\right.$ or 102)). The significance of this work arises from the correlation of the experimentally determined structural and electrocatalytic properties of these particles with density functional theory (DFT) calculations. Specifically, we describe an experimental and theoretical study of $\mathrm{Pb}$ underpotential deposition (UPD) on $\mathrm{Au}_{147} \mathrm{DENs}$, the structure of both $\mathrm{Au}_{147} @ \mathrm{~Pb}_{n}$ and $\mathrm{Au}_{147} @ \mathrm{Pt}_{n}$ DENs, and the activity of these DENs for the oxygen reduction reaction (ORR). DFT calculations show that $\mathrm{Pb}$ binding is stronger on the (100) facets of $\mathrm{Au}$ as compared to (111), and the calculated deposition and stripping potentials are consistent with those measured experimentally. Galvanic exchange is used to replace the surface $\mathrm{Pb}$ atoms with $\mathrm{Pt}$, and a surface distortion is found for $\mathrm{Au}_{147} @ \mathrm{Pt}_{n}$ particles using molecular dynamics simulations in which the Pt-covered (100) facets shear into (111) diamond structures. DFT calculations of oxygen binding show that the distorted surfaces are the most active for the ORR, and that their activity is similar regardless of the Pt coverage. These calculations are consistent with rotating ring-disk voltammetry measurements.

\section{Introduction}

In this paper we report the electrochemical synthesis of core@shell dendrimer-encapsulated nanoparticles (DENs) consisting of cores containing $147 \mathrm{Au}$ atoms $\left(\mathrm{Au}_{147}\right)$ and $\mathrm{Pt}$ shells having $\sim 54$ or $\sim 102$ atoms $\left(\mathrm{Au}_{147} @ \mathrm{Pt}_{n}(n=54\right.$ or 102)). The significance of this work arises from the correlation of the experimentally determined structural and electrocatalytic properties of these particles with density functional theory (DFT) calculations. Specifically, we describe an experimental and theoretical study of $\mathrm{Pb}$ underpotential deposition (UPD) on $\mathrm{Au}_{147}$ DENs, the structure of both $\mathrm{Au}_{147} @ \mathrm{~Pb}_{n}$ and $\mathrm{Au}_{147} @ \mathrm{Pt}_{n} \mathrm{DENs}$, and the activity of these DENs for the oxygen reduction reaction (ORR). Our findings illustrate how the coupling of DENs with DFT calculations serves as a good model for understanding electrocatalysis at a fundamental level.

\footnotetext{
${ }^{a}$ Department of Chemistry and Biochemistry, The University of Texas at Austin, 1 University Station, A5300, Austin, TX, 78712-0165, USA. E-mail: crooks@cm.utexas.edu; henkelman@mail.utexas.edu; Tel: 512-471-4179; 512-475-8674; Fax: 512-471-4179; 512-475-8674

${ }^{b}$ Center for Electrochemistry, The University of Texas at Austin, 1 University Station, A5300, Austin, TX, 78712-0165, USA

${ }^{c}$ Texas Materials Institute, The University of Texas at Austin, 1 University Station, A5300, Austin, TX, 78712-0165, USA

${ }^{d}$ Institute for Computational and Engineering Sciences, The University of Texas at Austin, 1 University Station, A5300, Austin, TX, 78712-0165, USA

$\dagger$ Electronic supplementary information (ESI) available. See DOI: $10.1039 / \mathrm{c} 2 \mathrm{sc} 00971 \mathrm{~d}$
}

DENs are synthesized by sequestering metal ions within the interior of poly(amidoamine) (PAMAM) dendrimers, followed by chemical reduction of the metal-ion/dendrimer complex with a reducing agent such as borohydride. ${ }^{1-4}$ Variations of this homogeneous synthetic method have yielded bimetallic DENs having different configurations, including random alloy and core@shell structures. ${ }^{5}$ We have also developed electrochemical methods for synthesizing core@shell DENs. ${ }^{6,7}$ DENs have been used to study electrocatalysis since $2005 .^{8}$ They are valuable for such studies for the following reasons. First, their size, composition, and structure can be precisely controlled. ${ }^{9,10}$ Second, the dendrimers stabilize the encapsulated nanoparticles and provide a handle for linking them to an electrode surface, but they do not interfere significantly with reactions on the particle surface. ${ }^{8}$ Third, DENs are in a size range (1-2 nm diameter) that makes it possible to directly compare theoretical and experimental results from structural and catalytic studies.

We have recently published several studies that are relevant to the results reported here. First, we described the synthesis and properties of $\mathrm{Au}_{147} @$ Pt DENs and demonstrated that they are electrocatalytically active for the ORR. ${ }^{6}$ These core@shell DENs were prepared by the UPD of $\mathrm{Cu}$ onto the surface of a Au core containing 147 atoms, followed by galvanic exchange of the $\mathrm{Cu}$ UPD layer for Pt. Second, we published a pair of comprehensive experimental and theoretical structural studies of $\mathrm{Cu}$ UPD onto Pt DENs consisting of $\sim 55$ to $\sim 225$ atoms. ${ }^{7,11}$ Finally, we reported on cluster-based DFT calculations of the structure and ORR activity of bimetallic nanoparticles in the same size range 
used for the experimental DEN studies. ${ }^{12}$ In contrast to these earlier studies, we now report a direct correlation between the experimentally determined structural and catalytic properties of DENs and first-principles calculations of materials having the same nominal structures and compositions.

Core@shell nanostructures are important because they exhibit tunable properties arising from the ability of the core metal to influence the properties of the shell. ${ }^{12-16}$ This phenomenon has been applied to electrocatalytic ${ }^{14,15,17}$ and spectroscopic applications. ${ }^{16}$ Early examples demonstrating the importance of Pt-shell nanoparticles as active electrocatalysts for the ORR were reported by Adzic and coworkers. ${ }^{14,15,18}$ The relationship between bimetallic nanoparticle structure and catalytic activity has been correlated to DFT calculations by a number of groups. ${ }^{17,19-21}$ Notably, Nørskov and coworkers have demonstrated trends in oxygen reduction electrocatalyst activity based on the binding energy of oxygen and other reaction intermediates to the metal surface. ${ }^{22,23}$

$\mathrm{Pb}$ UPD onto bulk Au surfaces, as well as onto Au nanostructures, has been studied extensively by Feliu and coworkers. ${ }^{24-26}$ They have shown that $\mathrm{Pb}$ UPD onto $\mathrm{Au}$ is a surface-selective reaction and that the morphology of the $\mathrm{Au}$ surface can be determined by analyzing voltammetric UPD peaks. With regard to nanoparticles, Feliu and his group have shown that the location of voltammetric $\mathrm{Pb}$ UPD peaks for welldefined single-crystal surfaces can be related to peak positions derived from nanoparticles, and that this correspondence can be used to help elucidate details of nanoparticle surface structure. ${ }^{26}$ One fact to emerge from these studies is that Pb UPD occurs on the low-index faces of $\mathrm{Au}$ in the following order: first $\mathrm{Au}(110)$, then $\mathrm{Au}(100)$, and finally $\mathrm{Au}(111){ }^{26}$

In the present paper, we show that Au DENs containing an average of $\sim 147$ atoms are active for UPD and that particular facets on these materials can be selectively decorated with $\mathrm{Pb}$. Specifically, a single monolayer of $\mathrm{Pb}$ is deposited first on the $\mathrm{Au}(100)$ facet, and then, at more negative potentials, the $\mathrm{Au}(111)$ facet. A principal outcome of this study is that the measured electrochemical potentials at which UPD occur are in good agreement with those determined by DFT modeling. We also found that UPD Pb deposited onto only the (100) facet, or both the (100) and (111) facets of $\mathrm{Au}_{147} \mathrm{DENs}$, could be exchanged for Pt. This galvanic exchange reaction results in $\mathrm{Au}_{147} @ \mathrm{Pt}_{n} \mathrm{DENs}$, where $n=54$ or 102, respectively. Interestingly, the experimentally determined ORR activities for both $\mathrm{Au}_{147} @ \mathrm{Pt}_{54}$ and $\mathrm{Au}_{147} @ \mathrm{Pt}_{102}$ are very similar. This finding is interpreted in terms of DFT oxygen binding energy calculations on models of the corresponding particles. While these particles may not necessarily be practical ORR catalysts, they offer the ability to study the ORR on a fundamental level. Taken together, the results presented here indicate that DENs are good nanoparticle models for correlating DFT calculations with experimental measurements.

\section{Experimental section}

\section{Chemicals}

Amine-terminated, sixth-generation PAMAM dendrimers $\left(\mathrm{G} 6-\mathrm{NH}_{2}\right)$ in methanol were purchased from Dendritech, Inc.
(Midland, MI). The methanol was evaporated under vacuum and the dendrimer was reconstituted in $\mathrm{H}_{2} \mathrm{O}$ at a concentration of $100 \mu \mathrm{M}$. The following chemicals were purchased from SigmaAldrich: $\mathrm{HAuCl}_{4}, \mathrm{~K}_{2} \mathrm{PtCl}_{4}, \mathrm{~Pb}\left(\mathrm{NO}_{3}\right)_{2}, \mathrm{NaBH}_{4}, \mathrm{NaOH}$, and ultrapure $\mathrm{HClO}_{4}$. Solutions were prepared using high-purity water obtained from a Millipore Milli-Q water system (18.2 M $\Omega$ $\mathrm{cm})$. Ultra-high-purity $\mathrm{N}_{2}$ and $\mathrm{O}_{2}(99.999 \%)$ were purchased from Praxair. All chemicals were used as received.

\section{Synthesis of Au DENs}

Au DENs were synthesized using a method similar to one reported previously. ${ }^{27}$ Typically, $20.0 \mathrm{~mL}$ of $2.0 \mu \mathrm{M}$ G6- $\mathrm{NH}_{2}\left(\mathrm{Au}_{147}\right)$ were prepared by adding 147 equiv. of $\mathrm{HAuCl}_{4}$ to a stirred solution containing $2.0 \mu \mathrm{M}$ G6- $\mathrm{NH}_{2}$. The $\mathrm{Au}^{3+}$ was allowed to complex with the dendrimer for $10 \mathrm{~min}$, and then a 10 -fold excess of $\mathrm{NaBH}_{4}$ in $0.30 \mathrm{M} \mathrm{NaOH}$ was added to reduce the G6- $\mathrm{NH}_{2}\left(\mathrm{Au}^{3+}\right)_{147}$ precursor to G6-NH$\left(\mathrm{Au}_{147}\right)$ DENs. This solution was stirred in air for $12 \mathrm{~h}$ to deactivate excess $\mathrm{BH}_{4}^{-}$, and the resulting DENs were used without further purification.

\section{Characterization}

UV-vis spectra were obtained using a Hewlett-Packard 8453 spectrometer. The cuvette path length was $0.200 \mathrm{~cm}$ and the spectra were background corrected using an aqueous solution of $2.0 \mu \mathrm{M}$ G6- $\mathrm{NH}_{2}$ dendrimer. TEM images of $\mathrm{G} 6-\mathrm{NH}_{2}\left(\mathrm{Au}_{147}\right)$ DENs were obtained using a JEOL 2010F TEM. Carbon-coated copper TEM grids (400 mesh) were purchased from Electron Microscopy Sciences. TEM grids were prepared by dropping $4.0 \mu \mathrm{L}$ of a $2.0 \mu \mathrm{M}$ G6- $\mathrm{NH}_{2}\left(\mathrm{Au}_{147}\right)$ DENs solution onto the grid and drying in a desiccator. TEM images of the of G6- $\mathrm{NH}_{2}-$ $\left(\mathrm{Au}_{147} @ \mathrm{Pt}_{102}\right)$ DENs were obtained using both the JEOL 2010F TEM and a Hitachi HD2700C aberration-corrected STEM. The TEM grid preparation for the G6- $\mathrm{NH}_{2}\left(\mathrm{Au}_{147} @ \mathrm{Pt}_{102}\right)$ DENs is discussed later.

\section{Electrochemistry}

Electrochemical measurements were performed using a $\mathrm{CH}$ Instruments 1202B potentiostat (Austin, TX, USA). All potentials were recorded and are reported versus a $\mathrm{Hg} / \mathrm{Hg}_{2} \mathrm{SO}_{4}$ reference electrode ( $\mathrm{CH}$ Instruments) unless otherwise noted. This electrode was calibrated against an eDAQ Hydroflex hydrogen reference electrode each day to ensure accurate potential control. Rotating ring-disk voltammetry (RRDV) was carried out using a AFASR rotator (Pine Instruments) and a Pine Instruments E7R9 series working electrode (5.61 mm-diameter glassy carbon disk and $0.84 \mathrm{~mm}$ wide Pt ring).

The Au DENs were immobilized on the electrode surface as follows. The $\mathrm{G} 6-\mathrm{NH}_{2}\left(\mathrm{Au}_{147}\right) \mathrm{DENs}$ were dissolved in an aqueous solution containing $20 \%$ isopropyl alcohol and then sonicated for $30 \mathrm{~min}$ with $2 \mathrm{mg} \mathrm{mL} \mathrm{mL}^{-1}$ Vulcan EC-72R carbon. Next, $6.0 \mu \mathrm{L}$ of this catalyst ink was pipetted onto the glassy carbon disk of a freshly polished rotating ring-disk electrode (RRDE). Finally, the catalyst was dried in air at room temperature $(23 \pm 3 \mathrm{C})$. 


\section{DFT calculations}

DFT was used to calculate the deposition process of Pb UPD on $\mathrm{Au}_{147}$ as well as the structures and oxygen binding energies to the $\mathrm{Au}_{147} @ \mathrm{Pt}_{\mathrm{n}}$ particles. All calculations were performed with the VASP $\operatorname{code}^{28,29}$ where electron correlation was evaluated within the generalized gradient approximation using the PW91 functional. $^{30}$ Core electrons were described with the projector augmented-wave method. ${ }^{31,32}$ Kohn-Sham wave functions for the valence electrons were expanded in a plane wave basis set with an energy cutoff of $250 \mathrm{eV}$. The energy cutoff was increased to $400 \mathrm{eV}$ to test for convergence, and oxygen binding energies were found to vary by less than $0.01 \mathrm{eV}$. Spin polarization was tested and used as required.

The $\mathrm{Au}_{147}$ particles were modeled as face-centered cubic (FCC) crystallites in the shape of a cuboctahedron having 6 (100) facets and 8 (111) facets. The structures of $\mathrm{Au}_{147} @ \mathrm{~Pb}$ and $\mathrm{Au}_{147} @$ Pt were built by attaching atoms on the facets of the Au nanoparticles. In all calculations, the nanoparticles were isolated in a cubic box having edge lengths of $28 \AA$. The vacuum gap in all directions was large enough to avoid artificial interactions between periodic images.

\section{Results and discussion}

\section{Characterization of G6- $\mathrm{NH}_{2}\left(\mathrm{Au}_{147}\right)$ DENs}

The synthesis of $\mathrm{Au}_{147} \mathrm{DEN}$ cores is described in the Experimental Section. These DENs were characterized using UV-vis spectroscopy and TEM to ensure their size and degree of monodispersity were consistent with previous reports (ESI, Figure $\mathrm{S} 1 \dagger)$. The TEM data indicate a diameter of $1.5 \pm 0.2 \mathrm{~nm}$, which is very close to the calculated value for a 147-atom cuboctahedron of $1.6 \mathrm{~nm} .{ }^{10}$ The very weak plasmon peak in the $\mathrm{UV}$-vis spectrum also indicates a Au particle size of $<2 \mathrm{~nm} .{ }^{27}$

\section{Electrochemical properties of $\mathrm{Au}_{147} \mathrm{DENs}$}

As described in the Experimental Section, electrochemical experiments were carried out using glassy carbon electrodes modified with Au DENs. The electroactive surface area of the Au DENs was determined by scanning the electrode potential 5 times between $-0.67 \mathrm{~V}$ and $+0.87 \mathrm{~V}$ in $\mathrm{N}_{2}$-saturated $0.10 \mathrm{M}$ $\mathrm{HClO}_{4}$. The positive scan limit was set to a potential just before bulk $\mathrm{Au}$ oxidation, and the negative limit was defined by the onset of $\mathrm{H}_{2}$ evolution on platinum. The final cycle of these scans is shown as the black cyclic voltammogram $(\mathrm{CV})$ in Fig. 1. The onset of $\mathrm{Au}$ surface oxidation is at $+0.50 \mathrm{~V}$, and upon scan reversal the surface oxide is reduced between $+0.50 \mathrm{~V}$ and $+0.10 \mathrm{~V}$. The charge under the reduction peak corresponds to a total Au surface area of $0.29 \mathrm{~cm}^{2}$. This value assumes a chargeper-unit-area of $390 \mu \mathrm{C} \mathrm{cm}$ ch $^{-2}$ which has been established for bulk, polycrystalline $\mathrm{Au}^{33}$ and which we have used previously to estimate the surface area of DENs. ${ }^{6}$

\section{Pb UPD onto G6- $\mathrm{NH}_{2}\left(\mathrm{Au}_{147}\right)$ DENs}

$\mathrm{Pb}$ UPD onto the electrode-immobilized $\mathrm{Au}_{147}$ DENs was carried out in a $\mathrm{N}_{2}$-saturated aqueous solution containing $1.0 \mathrm{mM}$ $\mathrm{Pb}\left(\mathrm{NO}_{3}\right)_{2}$ and $0.10 \mathrm{M} \mathrm{HClO}_{4}$. Pb UPD and stripping (oxidation)

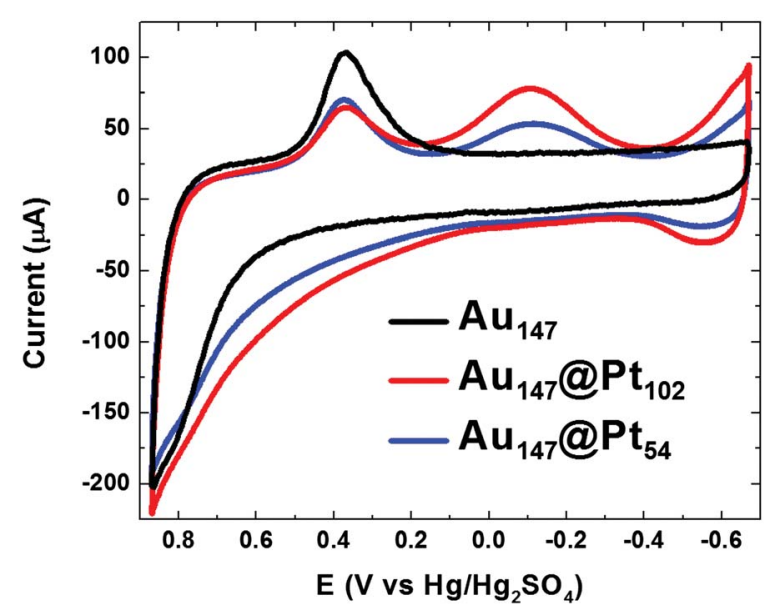

Fig. $1 \mathrm{CVs}$ of the indicated DEN-modified glassy carbon electrodes (geometrical area $=0.247 \mathrm{~cm}^{2}$ ). The scan rate was $100 \mathrm{mV} \mathrm{s}{ }^{-1}$ and the aqueous electrolyte contained $\mathrm{N}_{2}$-saturated $0.10 \mathrm{M} \mathrm{HClO}_{4}$.

were accomplished by scanning the electrode potential between 0.00 and $-0.90 \mathrm{~V}$, which is just before the onset of bulk $\mathrm{Pb}^{2+}$ reduction (Fig. 2, black trace). With one key exception, the major features of the $\mathrm{Pb}$ UPD voltammetry obtained using the $\mathrm{Au}_{147}$ DENs are similar to those observed on bulk Au (ESI, Figure S2 $\dagger$ ) or larger Au nanoparticle surfaces. ${ }^{24}$ For example, the potentials of the two most prominent $\mathrm{Pb}$ stripping peaks obtained using the $\mathrm{Au}_{147}$-modified electrode, are at -0.54 and $-0.69 \mathrm{~V}$. These values compare well those associated with $\mathrm{Pb}$ stripping from the (100) and (111) facets of bulk, polycrystalline $\mathrm{Au}$ : -0.60 and $-0.67 \mathrm{~V}$, respectively (Figure S2 $\dagger$ ) ${ }^{26}$ Importantly, however, the peak observed for $\mathrm{Pb}$ stripping from the $\mathrm{Au}(110)$ facets of the polycrystalline electrode $(-0.40 \mathrm{~V})$ is absent on the $\mathrm{Au}_{147}$ DENs. All of these observations are reassuringly consistent with our contention that $\mathrm{Au}_{147} \mathrm{DENs}$ have a cuboctahedral structure, because in this case the (100) and (111) facets are present while (110) facets are absent.

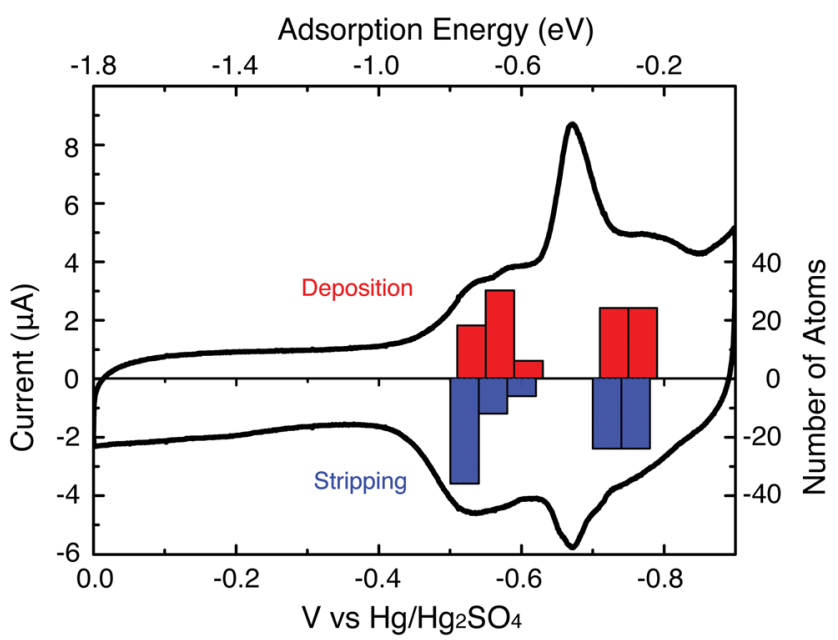

Fig. 2 A CV showing the Pb UPD process at a $\mathrm{Au}_{147}$ DEN-modified glassy carbon electrode. The scan rate was $5 \mathrm{mV} \mathrm{s}^{-1}$ and the aqueous electrolyte solution contained $1.0 \mathrm{mM} \mathrm{Pb}\left(\mathrm{NO}_{3}\right)_{2}$ in $0.10 \mathrm{M} \mathrm{HClO}_{4}$. The DFT-calculated potentials for $\mathrm{Pb}$ deposition (red bars) and stripping (blue bars) are also shown. 
The coverage of UPD Pb on $\mathrm{Au}_{147}$ DENs was determined by measuring the charge required to strip UPD $\mathrm{Pb}$ from the $\mathrm{Au}$ surface (Fig. 2), and then converting this to surface area using a calculated conversion factor of $413 \mu \mathrm{C} \mathrm{cm}^{-2}$ (see ESI $\dagger$ ). The resulting $\mathrm{Pb}$ surface area, $0.33 \mathrm{~cm}^{2}$, divided by the initial $\mathrm{Au}$ surface area (vide supra, $0.29 \mathrm{~cm}^{2}$ ) is defined as $\theta_{\mathrm{Pb}}{ }^{7}$ The value of $\theta_{\mathrm{Pb}}$ is equivalent to the number of $\mathrm{Pb}$ atoms in the UPD layer divided by the number of underlying $\mathrm{Au}$ atoms, because $\mathrm{Pb}$ forms a commensurate layer on the small Au domains. The experimentally determined value of $\theta_{\mathrm{Pb}}(1.14)$ is very close to that calculated $\left(\theta_{\mathrm{Pb}}=1.11\right)$ using a model that places $102 \mathrm{UPD} \mathrm{Pb}$ atoms (48 $\mathrm{Pb}$ atoms on the $8 \mathrm{Au}$ (111) facets and $54 \mathrm{~Pb}$ atoms on the $6 \mathrm{Au}$ (100) facets) onto the 92 surface atoms of $\mathrm{Au}_{147}$ (Fig. 3b).

\section{Pb UPD DFT calculations}

$\mathrm{Pb}$ UPD was modeled on $\mathrm{Au}_{147}$ particles using DFT calculations. First, the stability of $\mathrm{Pb}$ monolayers on the (100) and (111) facets was investigated by comparing two models. In the first model, each of the $6 \mathrm{Au}(100)$ facets were covered with $9 \mathrm{~Pb}$ atoms. In the second model, each of the $8 \mathrm{Au}(111)$ facets were covered with $6 \mathrm{~Pb}$ atoms. The average adsorption energies of the above two models were calculated using eqn (1).

$$
\left\langle E_{\mathrm{ad}}\right\rangle=\frac{1}{N}\left(E_{\mathrm{Au}_{147} \mathrm{~Pb}_{n}}-E_{\mathrm{Au}_{147}}-n E_{\mathrm{Pb}}\right)
$$

Here, $N$ is the number of $\mathrm{Pb}$ atoms on the shell (54 in the first model and 48 in the second), $E_{\mathrm{Au}_{147} \mathrm{~Pb}_{n}}$ is the energy of the $\mathrm{Au}_{147^{-}}$ core $\mathrm{Pb}$-shell particle, $E_{\mathrm{Au}_{147}}$ is the energy of the bare $\mathrm{Au}_{147}$ particle, and $E_{\mathrm{Pb}}$ is the energy of one $\mathrm{Pb}$ atom in the bulk metal. Using eqn (1), the average adsorption energy on the (100) facet was found to be $0.1 \mathrm{eV}$ per $\mathrm{Pb}$ atom lower than on the (111) facet, showing that $\mathrm{Pb}$ adlayers on (100) are more stable than those on the (111) facet. This finding is consistent with an increase in favorable $\mathrm{Pb}$-Au bonding of $\mathrm{Pb}$ on the (100) facet as compared to the (111) facet, and hence our assignment of the UPD peaks shown in Fig. 2. Due to the high energies of the edge and corner sites, Pb UPD does not occur there. That is, the energy of adsorption of $\mathrm{Pb}$ on the edge or corner sites is weaker than the energy of adsorption of $\mathrm{Pb}$ on a bulk $\mathrm{Pb}$ surface.

To model the $\mathrm{Pb}$ UPD process in detail, an atom-by-atom deposition calculation was done. $\mathrm{Pb}$ atoms were successively added to the lowest energy site on the Au particle, and the particle was relaxed before the addition of the next atom. The adsorption energy of the $n^{\text {th }} \mathrm{Pb}$ atom, $E_{\mathrm{ad}}(n)$, was calculated using eqn (2).

$$
E_{\mathrm{ad}}(n)=E_{\mathrm{Au}_{147} \mathrm{~Pb}}-E_{\mathrm{Au}_{147} \mathrm{~Pb}_{n-1}}-E_{\mathrm{Pb}}
$$

The calculated $E_{\text {ad }}$ values of each successive $\mathrm{Pb}$ atom binding site on (100) and (111) facets are plotted in Figure S3. $\dagger$ The first (or lowest energy) binding sites on the $\mathrm{Au}_{147}$ particle are on the (100) facets. Once the (100) facet sites are covered, the next $\mathrm{Pb}$ atoms deposit on the (111) sites. This means that the order of facet decoration on $\mathrm{Au}_{147}$ is consistent with bulk $\mathrm{Au}$ and larger Au nanoparticles. ${ }^{24}$

The values of $E_{\mathrm{ad}}$ were converted to potentials, $V_{\mathrm{PF}}^{\mathrm{DFT}}$, for comparison with the experimental voltammograms. For this conversion, we assume that the binding energy per atom in bulk $\mathrm{Pb}$ corresponds to the onset potential of bulk $\mathrm{Pb}$ deposition. The DFT-calculated potential is given by eqn (3).

$$
V_{\mathrm{Pb}}^{\mathrm{DFT}}(n)=V_{\mathrm{Pb}-\text { bulk }}^{\mathrm{Exp}}-\frac{1}{2} E_{\mathrm{ad}}(n)
$$

Here $V_{\mathrm{Pb}-\text { bulk }}^{\mathrm{Ex}}$ is the experimentally measured $\mathrm{Pb}$ bulk deposition potential $(-0.90 \mathrm{~V})$, and the factor of $1 / 2$ accounts for the two-electron $\mathrm{Pb}$ deposition and stripping process.

(a) partial shell
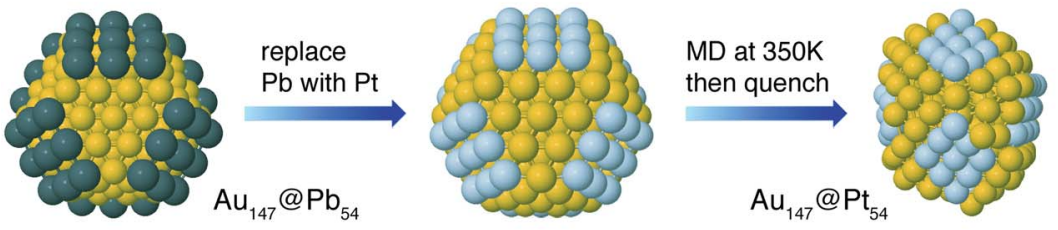

(b) full shell
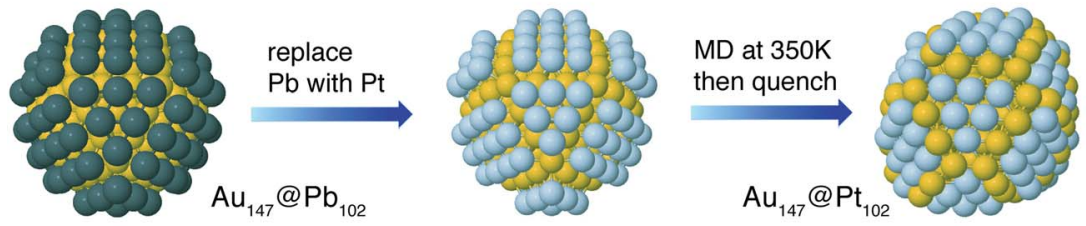

(c) O binding
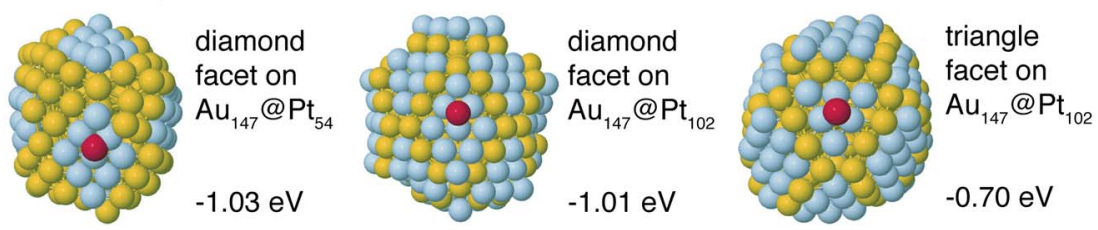

Fig. 3 DFT-calculated structures for (a) $\mathrm{Au}_{147} @ \mathrm{~Pb}_{54}$ and $\mathrm{Au}_{147} @ \mathrm{Pt}_{54}$ DENs and (b) $\mathrm{Au}_{147} @ \mathrm{~Pb}_{102}$ and $\mathrm{Au}_{147} @ \mathrm{Pt}_{102} \mathrm{DENs}$ (c) Oxygen binding sites and energies for $\mathrm{Au}_{147} @ \mathrm{Pt}_{54}$ and $\mathrm{Au}_{147} @ \mathrm{Pt}_{102}$ DENs. 
Fig. 2 compares a histogram of $V_{\mathrm{Pb}}^{\mathrm{DFT}}$ values for deposition and stripping of $\mathrm{Pb}$ atoms on $\mathrm{Au}_{147}$ with the UPD voltammogram. Based upon the order of deposition, and the separation of the peaks corresponding to UPD on the (100) and (111) facets, we constructed partially and fully covered models for the $\mathrm{Au}_{147} @ \mathrm{~Pb}_{n}$ particles (left side of frames a and b, Fig. 3). In the partially covered $\mathrm{Au}_{147} @ \mathrm{~Pb}_{54}$ model, the 6 (100) facets of the $\mathrm{Au}_{147}$ core are covered by $9 \mathrm{~Pb}$ atoms. In the fully covered $\mathrm{Au}_{147} @ \mathrm{~Pb}_{102}$ model, the $\mathrm{Au}_{147}$ core has an additional $6 \mathrm{~Pb}$ atoms on each of the 8 (111) facets.

\section{Synthesis of Au@Pt ${ }_{n}$ DENs}

A full or partial Pt shell can be added to the surface of $\mathrm{Au}_{147}$ particles via galvanic exchange of UPD $\mathrm{Pb}$. Monolayer $\mathrm{Pt}$ deposition on bulk Au surfaces is thought to be conformal, although thicker layers result in island growth. ${ }^{34,35}$ It follows that displacement of a $\mathrm{Pb}$ monolayer on $\mathrm{Au}$ DENs will result in a conformal Pt layer too. The data presented in this section is consistent with this expectation.

To avoid oxidation of the intermediate UPD $\mathrm{Pb}$ layer prior to galvanic exchange, the entire electrosynthesis was completed without removing the DEN-modified electrode from the $\mathrm{N}_{2}$-purged electrolyte solution. In addition, the electrode was rotated at 1600 RPM to ensure a high flux of the electrolyte solution to the electrode surface throughout the following electrosynthetic procedure. First, the disk of a RRDE was functionalized with $\mathrm{Au}_{147}$ DENs immobilized on Vulcan carbon as discussed earlier. Second, the disk electrode was held at the open circuit potential (OCP) for $5 \mathrm{~min}$ in a solution containing $100 \mathrm{~mL}$ of $0.10 \mathrm{M} \mathrm{HClO}_{4}$ and $1.0 \mathrm{mM} \mathrm{Pb}\left(\mathrm{NO}_{3}\right)_{2}$, and then its potential was stepped to $-0.85 \mathrm{~V}$ for $3 \mathrm{~s}$ to facilitate the UPD of a complete monolayer of $\mathrm{Pb}$ on the $\mathrm{Au}_{147}$ DENs. Third, the electrode was returned to the OCP, and then $10 \mathrm{~mL}$ of a $1.0 \mathrm{mM}$ $\mathrm{K}_{2} \mathrm{PtCl}_{4}$ solution was added to the solution to initiate galvanic exchange of UPD $\mathrm{Pb}$ for Pt. The OCP was monitored for $5 \mathrm{~min}$ following the addition of $\mathrm{Pt}^{2+}$ to the solution to confirm the galvanic exchange reaction (Figure $\mathrm{S} 4 \dagger$ ). Next, the electrode was removed from solution and rinsed thoroughly with $\mathrm{H}_{2} \mathrm{O}$. The electrode was then rotated at 1600 RPM in ultrapure $\mathrm{H}_{2} \mathrm{O}$ for 5 min, followed by $0.10 \mathrm{M} \mathrm{HClO}_{4}$ for $5 \mathrm{~min}$, to remove any free metal ions from the dendrimer. We refer to the resulting DENs as $\mathrm{Au}_{147} @ \mathrm{Pt}_{102}$. To prepare a partial Pt monolayer on $\mathrm{Au}_{147} \mathrm{DENs}$, the same UPD and galvanic exchange processes were used, except the electrode potential for preparing the $\mathrm{Pb}$ UPD layer was set to $-0.63 \mathrm{~V}$. This potential corresponds to $\mathrm{Pb}$ deposition on just the $\mathrm{Au}(100)$ facets. These partial-monolayer DENs are denoted $\mathrm{Au}_{147} @ \mathrm{Pt}_{54}$.

The $\mathrm{Au}_{147} @ \mathrm{Pt}_{102}$ DENs were imaged by TEM to verify their size and degree of monodispersity following addition of the $\mathrm{Pt}$ shell. Somewhat surprisingly, very good micrographs could be obtained by simply wiping a TEM grid across the electrode surface, which apparently dislodges flakes of Vulcan carbon onto which the DENs are adsorbed. A representative image of $\mathrm{Au}_{147} @ \mathrm{Pt}_{102}$ is provided in Fig. 4a. The average measured particle size is $2.3 \pm 0.4 \mathrm{~nm}$, reflecting the addition of a $\mathrm{Pt}$ monolayer to the original $\mathrm{Au}_{147}$ cores $(1.5 \pm 0.2 \mathrm{~nm})$. The calculated size of $\mathrm{Au}_{147} @ \mathrm{Pt}_{102} \mathrm{DENs}$ is $\sim 2.1 \mathrm{~nm}$. It is important to note that the particles remain relatively monodisperse after $\mathrm{Pb}$
UPD and galvanic exchange, which suggests they remain encapsulated within the protective dendrimer throughout electrosynthesis.

Information about the distribution and identity of atoms on the surfaces of the $\mathrm{Au}_{147} @ \mathrm{Pt}_{102}$ and $\mathrm{Au}_{147} @ \mathrm{Pt}_{54}$ DENs can be obtained using $\mathrm{CV}$. The results of this analysis are provided in

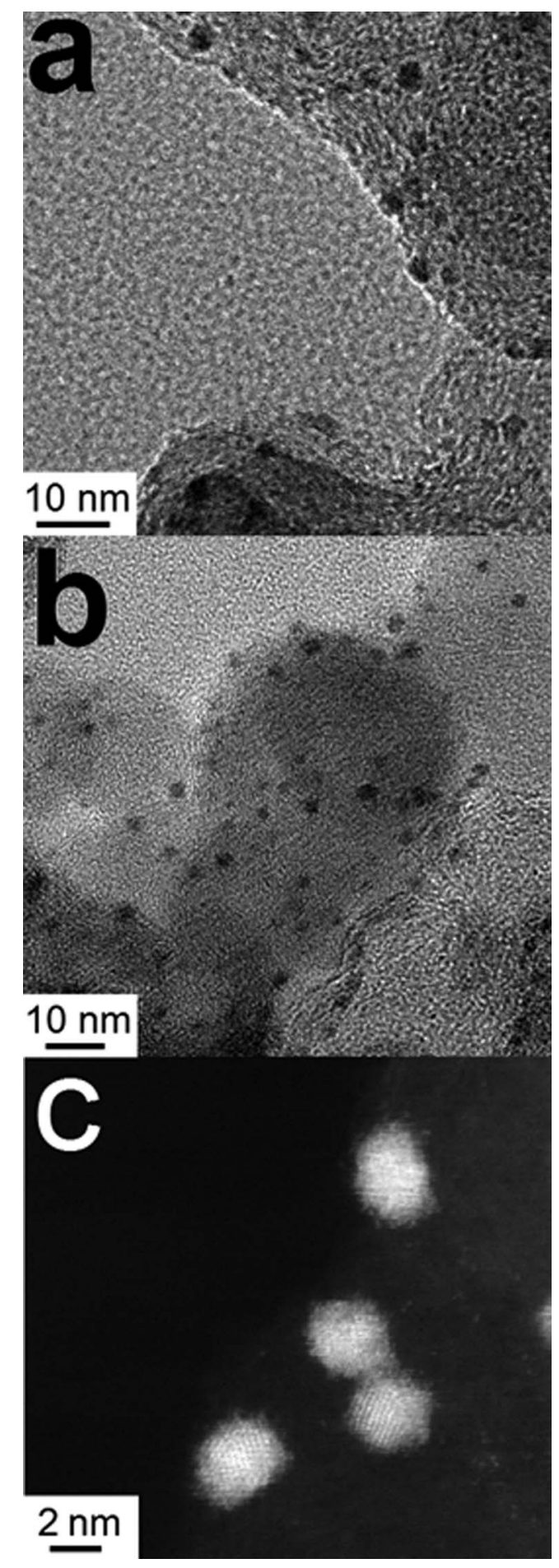

Fig. 4 TEM micrographs of $\mathrm{Au}_{147} @ \mathrm{Pt}_{102}$ DENs (a) before and ( $\mathrm{b}$ and c) after being used for the ORR. The particle diameters before and after the ORR were $2.3 \pm 0.4$ and $2.4 \pm 0.4 \mathrm{~nm}$, respectively. 
Fig. 1 alongside a $\mathrm{CV}$ for the original $\mathrm{Au}_{147}$ DEN cores. The CVs of the $\mathrm{Au}_{147} @ \mathrm{Pt}_{n}$ DENs have several features in common. For example, the $\mathrm{Pt}$ shell begins to oxidize well negative of the onset potential for surface oxidation of the $\mathrm{Au}_{147}$ DENs $(+0.1 \mathrm{~V}$ vs. $+0.5 \mathrm{~V}$, respectively). Upon scan reversal, reduction of the Au surface oxide occurs at about the same potential observed for $\mathrm{Au}_{147} \mathrm{DENs}$, but the peak height is attenuated because Pt masks some of the surface Au atoms. At more negative potentials, a peak is observed for reduction of $\mathrm{Pt}$ oxide, but note that this peak is absent for the $\mathrm{Au}_{147}$ DENs. Likewise, $\mathrm{H}$ atom adsorption and desorption features appear negative of $-0.4 \mathrm{~V}$ for the $\mathrm{Au}_{147} @ \mathrm{Pt}_{n}$ DENs but are absent for the $\mathrm{Au}_{147}$ DENs. The features here are not as pronounced as they are on bulk Pt, but they are consistent with previous reports of $\mathrm{H}$ adsorption and desorption on monometallic Pt DENs in the same size range. ${ }^{710}$ The important results of this analysis are that $\mathrm{Pb}$ UPD followed by galvanic exchange results in features characteristic of a Pt surface and impedes formation of $\mathrm{Au}$ oxide, thereby confirming formation of the $\mathrm{Au}_{147} @ \mathrm{Pt}_{n}$ DENs. $^{6}$

The surface coverage of $\mathrm{Pt}$ on $\mathrm{Au}_{147} @ \mathrm{Pt}_{n}$ DENs can be estimated by integrating the area under the hydrogen adsorption peaks in Fig. 1. This requires correction of the current for double-layer charging and an assumption about the relationship between charge and surface area. For the latter, we used the commonly accepted conversion factor of $210 \mu \mathrm{C} \mathrm{cm}^{-2},{ }^{36}$ but this value has only been confirmed for bulk surfaces and therefore is just a best estimate for DENs. As discussed earlier, the surface coverage of $\mathrm{Au}$ can also be estimated using the $\mathrm{Au}$ oxide reduction peak, which we integrated from the onset of the $\mathrm{Au}$ reduction to the onset of $\mathrm{Pt}$ oxide reduction. Using this analysis, the surface areas of $\mathrm{Pt}$ on the $\mathrm{Au}_{147} @ \mathrm{Pt}_{102}$ and $\mathrm{Au}_{147} @ \mathrm{Pt}_{54}$ DENs were determined to be 0.17 and $0.11 \mathrm{~cm}^{2}$, respectively, and the Au surface areas were 0.13 and $0.17 \mathrm{~cm}^{2}$, respectively. When the $\mathrm{Au}$ and $\mathrm{Pt}$ coverages are added together, the total surface areas are 0.30 and $0.28 \mathrm{~cm}^{2}$ for the $\mathrm{Au}_{147} @ \mathrm{Pt}_{102}$ and $\mathrm{Au}_{147} @ \mathrm{Pt}_{54} \mathrm{DENs}$, respectively. These areas are slightly larger than those of the original $\mathrm{Au}_{147}$ DENs $\left(0.29\right.$ and $0.27 \mathrm{~cm}^{2}$, respectively), which is consistent with addition of a $\mathrm{Pt}$ shell. Table 1 provides a summary of the electrochemically derived surface coverages of $\mathrm{Au}$ and $\mathrm{Pt}$ on the $\mathrm{Au}_{147}, \mathrm{Au}_{147} @ \mathrm{Pt}_{102}$, and $\mathrm{Au}_{147} @ \mathrm{Pt}_{54}$ DENs.

Table 1 Summary of Au and Pt surface areas determined by electrochemical methods

\begin{tabular}{lll}
\hline & $\mathrm{Au}_{147} @ \mathrm{Pt}_{102}$ & $\mathrm{Au}_{147} @ \mathrm{Pt}_{54}$ \\
\hline Initial Au 147 surface area & $0.29 \mathrm{~cm}^{2}$ & $0.27 \mathrm{~cm}^{2}$ \\
Final Au surface area & $0.13 \mathrm{~cm}^{2}$ & $0.17 \mathrm{~cm}^{2}$ \\
Final Pt surface area & $0.17 \mathrm{~cm}^{2}$ & $0.11 \mathrm{~cm}^{2}$ \\
Percent Surface Pt & $57 \%$ & $39 \%$ \\
Total Au@Pt surface area $^{b}$ & $0.30 \mathrm{~cm}^{2}$ & $0.28 \mathrm{~cm}^{2}$ \\
Percent surface area increase $^{c}$ & $3 \%$ & $4 \%$
\end{tabular}

${ }^{a}$ Percent surface $\mathrm{Pt}$ is calculated as the Pt electrochemical surface area divided by the total $\mathrm{Au}$ and $\mathrm{Pt}$ electrochemical surface area. ${ }^{b}$ Total $\mathrm{Au} @ \mathrm{Pt}$ surface area is the Au@Pt: Au surface area plus the Au@Pt: Pt surface area. ${ }^{c}$ Percent area increase is calculated as the total Au@Pt surface area divided by the starting $\mathrm{Au}_{147}$ surface area.

\section{Oxygen reduction reaction on $\mathrm{Au}_{147} @ \mathrm{Pt}_{n}$ DENs}

The activity of $\mathrm{Au}_{147} @ \mathrm{Pt}_{102}, \mathrm{Au}_{147} @ \mathrm{Pt}_{54}$, and $\mathrm{Au}_{147} \mathrm{DENs}$ for the ORR was determined using a RRDV method that $\mathrm{we}^{10}$ and others $^{36,37}$ have reported previously. Briefly, the DEN surfaces were cleaned electrochemically by cycling the electrode potential 20 times between 1.00 and $0.05 \mathrm{~V} v s$. RHE (unless otherwise noted, potentials in this section are reported $v s$. RHE to be consistent with previous reports). Next, the DEN-modified glassy carbon disk electrode was scanned from 0.05 to $1.00 \mathrm{~V}$ in freshly prepared, $\mathrm{O}_{2}$-saturated $0.10 \mathrm{M} \mathrm{HClO}_{4}$, while holding the ring at $+1.30 \mathrm{~V}$ to collect (oxidize) any peroxide generated at the disk. The measured disk and ring currents were background corrected by performing the same scan program in $\mathrm{N}_{2}$-saturated $0.10 \mathrm{M} \mathrm{HClO}_{4}$. The resulting polarization curves for the disk electrode are given in Fig. 5a and the corresponding ring currents are provided in Fig. 5 b.

The onset potential for the ORR for both $\mathrm{Au}_{147} @ \mathrm{Pt}_{102}$ and $\mathrm{Au}_{147} @ \mathrm{Pt}_{54} \mathrm{DENs}$ is at $\sim 0.9 \mathrm{~V}$, and the current attains limiting behavior at $\sim 0.5 \mathrm{~V}$. However, at slightly more negative potentials, a second current plateau is observed. Importantly, the onset of current for the ORR at the $\mathrm{Au}_{147}$-modified electrode (blue line, Fig. 5a) is coincident with the appearance of the second plateau observed for the $\mathrm{Au}_{147} @ \mathrm{Pt}_{n} \mathrm{DENs}$. We conclude that the first current plateau for the $\mathrm{Au}_{147} @ \mathrm{Pt}_{n}$ DENs arises from the ORR on the fraction of the DEN surface covered with Pt atoms, and the second plateau arises from the fraction covered with $\mathrm{Au}$

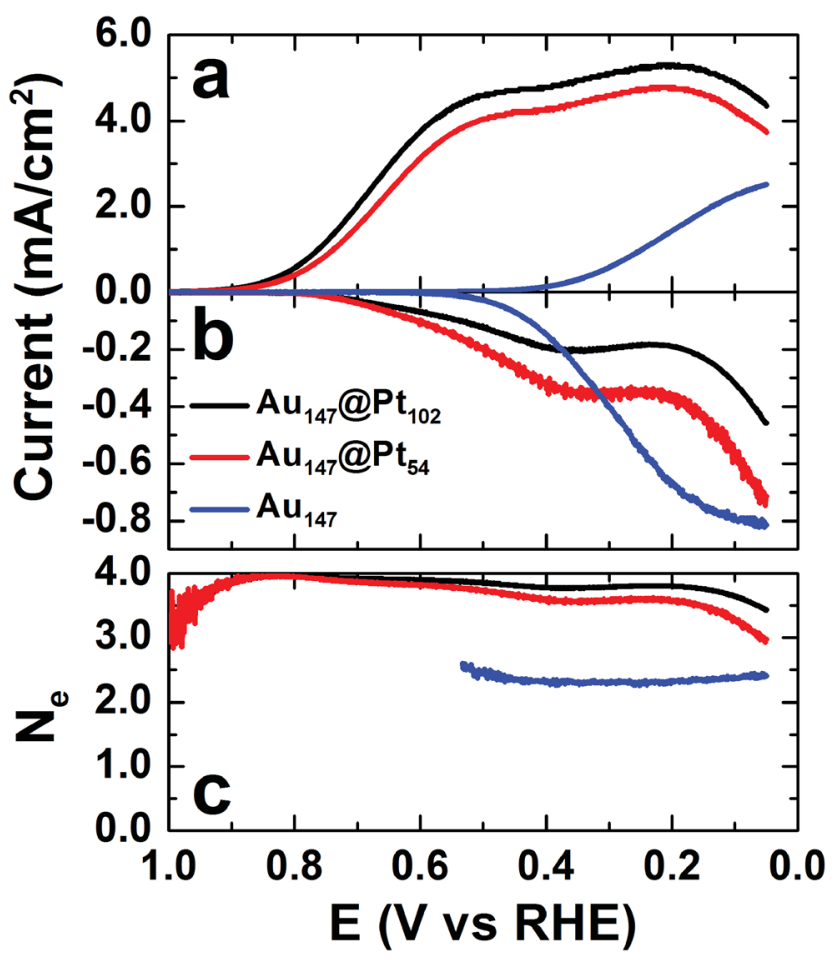

Fig. 5 (a) ORR polarization curves for the indicated DEN-modified glassy carbon electrodes. (b) Ring currents arising from the oxidation of peroxide generated at the disk electrode during the ORR. (c) The apparent number of electrons calculated from the disk and ring currents. The electrolyte solution was $\mathrm{O}_{2}$-saturated $0.10 \mathrm{M} \mathrm{HClO}_{4}$, the scan rate was $20 \mathrm{mV} \mathrm{s}^{-1}$, and the rotation rate was $1600 \mathrm{RPM}$. 
atoms. This observation strongly suggests that the ORR proceeds independently on the surface of the full or partial $\mathrm{Pt}$ shell and the exposed Au core (structural models are shown in Fig. 3).

The number of electrons $\left(N_{\mathrm{e}}\right)$ involved in the ORR was calculated using eqn (4), where $I_{\mathrm{R}}$ and $I_{\mathrm{D}}$ are the ring and disk currents, respectively. The ring collection efficiency was experimentally determined to be 0.37 .

$$
N_{\mathrm{e}}=4-\left(2 \times I_{\mathrm{R}}\right) /\left(0.37 \times I_{\mathrm{D}}\right)
$$

The value of $N_{\mathrm{e}}$ is plotted as a function of disk electrode potential in Fig. 5c. In the potential region corresponding to the limiting current, $N_{\mathrm{e}}=3.8$ and 3.6 for the $\mathrm{Au}_{147} @ \mathrm{Pt}_{102^{-}}$and $\mathrm{Au}_{147} @ \mathrm{Pt}_{54}$-modified electrodes, respectively. The slight decrease in $N_{\mathrm{e}}$ observed for the partial Pt shell can be attributed to peroxide generated on the exposed Au facets. ${ }^{38}$

Theoretical limiting currents for the ORR at $\mathrm{Au}_{147} @ \mathrm{Pt}_{n^{-}}$ modified electrodes can be calculated using the Levich equation (eqn (5)). ${ }^{10}$

$$
I_{\text {lim }}=0.20 \times N_{\mathrm{e}} \times F \times A_{\text {geo }} \times D_{\mathrm{O}}^{2 / 3} \times \omega^{1 / 2} \times \nu^{-1 / 6} \times C_{O}
$$

Here, $N_{\mathrm{e}}$ is given by eqn (4), $F$ is the Faraday constant, $A_{\text {geo }}$ is the geometrical area of the electrode glassy carbon electrode $\left(0.247 \mathrm{~cm}^{2}\right), D_{\mathrm{O}}$ is the diffusion coefficient of $\mathrm{O}_{2}$ in aqueous solution $\left(2.0 \times 10^{-5} \mathrm{~cm}^{2} \mathrm{~s}^{-1}\right), \omega$ is the rotation rate of the electrode (1600 RPM), $\nu$ is the kinematic viscosity of water at $25^{\circ} \mathrm{C}\left(1.0 \times 10^{-2} \mathrm{~cm}^{2} \mathrm{~s}^{-1}\right)$, and $C_{\mathrm{O}}$ is the saturation concentration of $\mathrm{O}_{2}$ in a dilute acid solution $\left(1.2 \times 10^{-6} \mathrm{~mol} \mathrm{~cm}^{-3}\right) .{ }^{10} \mathrm{Using}$ these values, the calculated $I_{\lim }$ for the full and partial shell electrocatalysts is 5.59 and $5.29 \mathrm{~mA} \mathrm{~cm}^{-2}$, respectively. The corresponding measured current densities are $I_{\text {lim }}=5.30$ and $4.78 \mathrm{~mA} \mathrm{~cm}^{-2}$, respectively, which are within $10 \%$ of the calculated values.

The kinetic currents $\left(I_{\mathrm{k}}\right)$ for the $\mathrm{Au}_{147} @ \mathrm{Pt}_{102^{-}}$and $\mathrm{Au}_{147} @ \mathrm{Pt}_{54}$-modified electrodes at $\mathrm{E}=0.80 \mathrm{~V}$ was calculated using eqn (6). ${ }^{36}$

$$
I_{k}=\left(I_{\lim } \times I_{0.8 V}\right) /\left(I_{\lim }-I_{0.8 V}\right)
$$

The resulting values of $I_{\mathrm{k}}$ were then normalized to the $\mathrm{Pt}$ surface areas of the electrocatalysts, determined using the hydrogen adsorption charge (vide supra), to yield specific activities of 0.92 and $0.98 \mathrm{~mA} \mathrm{~cm}{ }^{-2}$ and for the $\mathrm{Au}_{147} @ \mathrm{Pt}_{102}$ and $\mathrm{Au}_{147} @ \mathrm{Pt}_{54}$ electrocatalysts, respectively.

In the next section, we will correlate the experimentally determined ORR measurements to DFT calculations. For such a comparison to be valid, it is necessary to ensure that no gross changes in catalyst structure occurred during the electrochemical measurements. Accordingly, a TEM grid was wiped across the electrode surface to harvest $\mathrm{Au}_{147} @ \mathrm{Pt}_{102}$ DENs after the RRDV data in Fig. 5 were collected. Representative TEM micrographs of these post-catalysis $\mathrm{Au}_{147} @ \mathrm{Pt}_{102}$ DENs are shown in Fig. $4 \mathrm{~b}$ and 4c. The average DEN diameter was found to be $2.4 \pm 0.4 \mathrm{~nm}$, which compares well with the DEN diameter measured before catalysis $(2.3 \pm 0.4 \mathrm{~nm})$. The absence of agglomeration suggests that the DENs are stable and remain within their dendrimer hosts throughout the electrocatalytic experiments.

\section{DFT calculations of $\mathrm{Au}_{147} @ \mathrm{Pt}_{n}$ structure and ORR activity}

For simplicity, $\mathrm{Pb}$ atoms were assumed to be directly replaced by $\mathrm{Pt}$ in the galvanic exchange process. MD simulations were carried out on the $\mathrm{Au}_{147} @ \mathrm{Pt}_{102}$ and $\mathrm{Au}_{147} @ \mathrm{Pt}_{54}$ particles for $10 \mathrm{ps}$ at $350 \mathrm{~K}$ to allow them to escape from any shallow local minima. Forces from DFT were used for these dynamics, as well as in a subsequent minimization for comparison with the initial $\left(\mathrm{Au}_{147} @ \mathrm{~Pb}_{n}\right)$ structures. Fig. 3a shows the considerable deformation for the partial-shell structure induced by the short-time MD simulations, indicating the instability of the ordered structures upon substitution of the $\mathrm{Pb}$ shell atoms with $\mathrm{Pt}$. The deformation has two distinct features: First, Au atoms in the sublayer rise to the surface edge sites. Second, the original square (100) Pt facets deform to diamond-shaped (111) facets. The relaxed $\mathrm{Au}_{147} @ \mathrm{Pt}_{54}$ particle is $0.2 \mathrm{eV}$ per Pt atom lower in energy than the ordered structure. A similar distortion occurs on the full shell $\mathrm{Au}_{147} @ \mathrm{Pt}_{102}$ particle. The (100) ordered facets of the $\mathrm{Au}_{147} @ \mathrm{Pt}_{102}$ structure, shown in Fig. 3b, spontaneously deform to diamond-shaped (111) facets.

To better understand these deformations, we calculated the (100) and (111) surface energies of Pt, Au, and a Pt monolayer on $\mathrm{Au}$ using 4-layer slab models containing 9 atoms per layer. The results indicate that the surface energy of $\mathrm{Au}(111)$ is $0.11 \mathrm{eV}$ atom $^{-1}$ lower (more stable) than that of $\mathrm{Au}(100)$, and $\mathrm{Pt}(111)$ is $0.25 \mathrm{eV}$ atom $^{-1}$ lower than $\mathrm{Pt}(100)$. Moreover, the cohesive energy of a Pt monolayer on $\mathrm{Au}(111)$ is $0.17 \mathrm{eV}^{\text {atom }}{ }^{-1}$ lower than on $\mathrm{Au}(100)$. These two results account for the deformation of Pt-covered $\mathrm{Au}(100)$ facets to a (111) diamond structure by lowering of the Pt surface energy and increasing the stability of the particle.

To determine the catalytic activity of the $\mathrm{Au}_{147} @ \mathrm{Pt}_{n}$ particles, we rely on the binding energy of $\mathrm{O}$ as a descriptor for ORR activity. ${ }^{22,23}$ A volcano plot analysis of the ORR shows that the $\mathrm{O}$ binding energy on $\mathrm{Pt}(111)$ is near optimal. ${ }^{22}$ Fig. 3c shows $\mathrm{O}$ binding to hollow sites on different Pt facets of $\mathrm{Au}_{147} @ \mathrm{Pt}_{54}$ and $\mathrm{Au}_{147} @ \mathrm{Pt}_{102}$. Oxygen binding to the deformed diamond (111) facets of the two nanoparticle structures have similar values of -1.03 and $-1.01 \mathrm{eV}$, respectively. The triangular (111) facet of the $\mathrm{Au}_{147} @ \mathrm{Pt}_{102}$ particle has an $\mathrm{O}$ binding energy that is $0.3 \mathrm{eV}$ weaker. All of these $\mathrm{O}$ binding energies are weaker than for $\operatorname{Pt}(111)$, which was calculated with the slab model to be $-1.55 \mathrm{eV}$. This is in contrast to other reported cases where a $\mathrm{Pt}$ monolayer on a Au surface leads to a lattice expansion of the $\mathrm{Pt}$, and stronger binding of oxygen to the surface. ${ }^{39-41}$ In the present case, $\mathrm{Au}$ atoms that rise to the surface during the structural reorganization actually compress the small $\mathrm{Pt}(111)$ domains. The $\mathrm{Pt}-\mathrm{Pt}$ bond length in the diamond-shaped domains, as calculated from the DFT structures of $\mathrm{Au}_{147} @ \mathrm{Pt}_{54}$ and $\mathrm{Au}_{147} @ \mathrm{Pt}_{102}$, is 2.65 $\AA$, which is shorter than that of bulk Pt $(2.77 \AA)$. This compression of the $\mathrm{Pt}-\mathrm{Pt}$ bonds leads to a weaker binding of $\mathrm{O}$ on the nanoparticle Pt surface as compared to bulk Pt(111). ${ }^{39,40}$ Because $\mathrm{O}$ binding on the nanoparticle facets is weaker than on $\operatorname{Pt}(111)$, the particle facets are too noble to give optimal activity, and the ORR mechanism is limited by $\mathrm{O}-\mathrm{O}$ dissociation. However, the diamond facets (with stronger O-binding) are expected to have a higher activity than the triangular facets, so it is the diamond facets that are active for the ORR on both the $\mathrm{Au}_{147} @ \mathrm{Pt}_{102}$ and $\mathrm{Au}_{147} @ \mathrm{Pt}_{54}$ particles. Note also that the nearly 
identical calculated $\mathrm{O}$ binding energy for these two structures is consistent with the experimentally determined specific ORR activities measured for the partial and full shell $\mathrm{Au}_{147} @ \mathrm{Pt}_{n}$ DENs (vide supra).

\section{Summary and conclusions}

Here we have reported the electrochemical synthesis and electrocatalytic properties of $\mathrm{Au}_{147} @ \mathrm{Pt}_{n}$ DENs ( $n=0,54$, and 102), and correlated the experimental measurements to theoretical calculations. The synthesis of the $\mathrm{Au}_{147} @ \mathrm{Pt}_{\mathrm{n}} \mathrm{DENs}$ is carried out by first reducing $\mathrm{Pb}^{2+}$ via UPD, and then exchanging the resulting surface $\mathrm{Pb}$ atoms for $\mathrm{Pt}$ atoms. We model the $\mathrm{Au}_{147} \mathrm{DEN}$ cores as cuboctahedra and show that the UPD/galvanic exchange approach can be used to selectively decorate particular facets with Pt. DFT calculations accurately predict the potentials for $\mathrm{Pb}$ deposition onto the $\mathrm{Au}(100)$ and $\mathrm{Au}(111)$ facets of the $\mathrm{Au}_{147}$ DENs. Moreover, the structures of $\mathrm{Au}_{147} @ \mathrm{~Pb}_{n}$ and $\mathrm{Au}_{147} @ \mathrm{Pt}_{n}$ DENs having full and partial coverage were also predicted by theory. Ordered structures are observed for $\mathrm{Au}_{147} @ \mathrm{~Pb}_{n}$ DENs, while $\mathrm{Au}_{147} @ \mathrm{Pt}_{n}$ particles undergo a deformation such that all Pt surface atoms reorganize to (111) facet orientations. The experimentally measured electrocatalytic activities of $\mathrm{Au}_{147} @ \mathrm{Pt}_{n}$ DENs having full or partial shells ( $n=102$ and 54, respectively) were found to be similar. The calculations, which are based on the binding energy between $\mathrm{O}$ and $\mathrm{Pt}$, are in accord with this finding.

The most important result of this study is that core@shell DENs are good experimental models for testing the predictive power of first-principles calculations. This is because DENs are sufficiently small and structurally well-defined that direct correlations between theory and experiment can be made. In the present report we have reconciled the theory to experimental measurements, but our findings have been sufficiently encouraging that theory will lead the experiments as we move forward. The results of those studies will be reported in due course.

\section{Acknowledgements}

We gratefully acknowledge support from the Chemical Sciences, Geosciences, and Biosciences Division, Office of Basic Energy Sciences, Office of Science, U. S. Department of Energy (Contract: DE-FG02-09ER 16090). We thank Dr Dong Su (Brookhaven National Laboratory) for help with collection of the STEM micrographs and Dr J. P. Zhou (UT-Austin) for assistance with the other TEM measurements. RMC thanks the Robert A. Welch Foundation (Grant F-0032) for sustained support. GH would like to acknowledge support from the Robert A. Welch Foundation (Grant F-1601) and the W. A. "Tex" Moncrief, Jr. Endowment in Simulation-Based Engineering Sciences through Grand Challenge Faculty Fellowships from the Institute of Computational and Engineering Sciences at UT-Austin. The computational work was done primarily at the National Energy Research Scientific Computing Center and the Texas Advanced Computing Center.

\section{References}

1 R. W. J. Scott, O. M. Wilson and R. M. Crooks, J. Phys. Chem. B, 2005, 109, 692.

2 D. Yamamoto, S. Watanabe and M. T. Miyahara, Langmuir, 2010, 26, 2339

3 H. Lang, R. A. May, B. L. Iversen and B. D. Chandler, J. Am. Chem. Soc., 2003, 125, 14832.

4 M. Bernechea, S. García-Rodríguez, P. Terreros, E. de Jesús, J. L. G. Fierro and S. Rojas, J. Phys. Chem. C, 2011, 115, 1287.

5 V. S. Myers, M. G. Weir, E. V. Carino, D. F. Yancey, S. Pande and R. M. Crooks, Chem. Sci., 2011, 2, 1632.

6 D. F. Yancey, E. V. Carino and R. M. Crooks, J. Am. Chem. Soc., 2010, 132, 10988.

7 E. V. Carino and R. M. Crooks, Langmuir, 2011, 27, 4227.

8 H. Ye and R. M. Crooks, J. Am. Chem. Soc., 2005, 127, 4930.

9 H. Ye and R. M. Crooks, J. Am. Chem. Soc., 2007, 129, 3627.

10 H. Ye, J. A. Crooks and R. M. Crooks, Langmuir, 2007, 23, 11901.

11 E. V. Carino, H. Y. Kim, G. Henkelman and R. M. Crooks, J. Am. Chem. Soc., 2011, in press.

12 W. Tang and G. Henkelman, J. Chem. Phys., 2009, 130, 194504.

13 N. S. Froemming and G. Henkelman, J. Chem. Phys., 2009, 131, 234103.

14 J. X. Wang, H. Inada, L. Wu, Y. Zhu, Y. Choi, P. Liu, W.-P. Zhou and R. R. Adzic, J. Am. Chem. Soc., 2009, 131, 17298.

15 K. Gong, D. Su and R. R. Adzic, J. Am. Chem. Soc., 2010, 132, 14364.

16 S. Pande, S. K. Ghosh, S. Praharaj, S. Panigrahi, S. Basu, S. Jana, A. Pal, T. Tsukuda and T. Pal, J. Phys. Chem. C, 2007, 111, 10806.

17 P.-P. Fang, S. Duan, X.-D. Lin, J. R. Anema, J.-F. Li, O. Buriez, Y. Ding, F.-R. Fan, D.-Y. Wu, B. Ren, Z. L. Wang, C. Amatore and Z.-Q. Tian, Chem. Sci., 2011, 2, 531.

18 S. Ball, S. L. Burton, J. Fisher, R. O’Malley, B. Tessier, B. R. C. Theobald, D. Thompsett, W. P. Zhou, D. Su, Y. Zhu and R. Adzic, ECS Trans., 2009, 25, 1023.

19 A. U. Nilekar, Y. Xu, J. Zhang, M. B. Vukmirovic, K. Sasaki, R. R. Adzic and M. Mavrikakis, Top. Catal., 2007, 46, 276.

20 G. Barcaro, A. Fortunelli, M. Polak and L. Rubinovich, Nano Lett., 2011, 11, 1766.

21 F.-J. Lai, H.-L. Chou, L. S. Sarma, D.-Y. Wang, Y.-C. Lin, J.-F. Lee, B.-J. Hwang and C.-C. Chen, Nanoscale, 2010, 2, 573.

22 J. K. Nørskov, J. Rossmeisl, A. Logadottir, L. Lindqvist, J. R. Kitchin, T. Bligaard and H. Jonsson, J. Phys. Chem. B, 2004, 108, 17886.

23 J. K. Norskov, F. Abild-Pedersen, F. Studt and T. Bligaard, Proc. Natl. Acad. Sci. U. S. A., 2011, 108, 937.

24 J. Hernández, J. Solla-Gullón, E. Herrero, A. Aldaz and J. M. Feliu, J. Phys. Chem. B Lett., 2005, 109, 12651.

25 J. Hernández, J. Solla-Gullón, E. Herrero, A. Aldaz and J. M. Feliu, J. Phys. Chem. C, 2007, 111, 14078.

26 J. Hernández, J. Solla-Gullón, E. Herrero, J. M. Feliu and A. Aldaz, J. Nanosci. Nanotechnol., 2009, 9, 2256.

27 Y.-G. Kim, S.-K. Oh and R. M. Crooks, Chem. Mater., 2004, 16, 167.

28 G. Kresse, Phys. Rev. B: Condens. Matter, 2000, 62, 8295.

29 G. Kresse and J. Hafner, Surf. Sci., 2000, 459, 287.

30 J. P. Perdew and Y. Wang, Phys. Rev. B, 1992, 45, 13244.

31 P. E. Blochl, Phys. Rev. B: Condens. Matter, 1994, 50, 17953.

32 G. Kresse and D. Joubert, Phys. Rev. B, 1999, 59, 1758.

33 S. Trasatti and O. A. Petrii, Pure Appl. Chem., 1991, 63, 711.

34 Y. Ding, M. Chen and J. Erlebacher, J. Am. Chem. Soc., 2004, 126, 6876.

35 A. Mathur and J. Erlebacher, Surf. Sci., 2008, 602, 2863.

36 Y. Garsany, O. A. Baturina, K. E. Swider-Lyons and S. S. Kocha, Anal. Chem., 2010, 82, 6321.

37 K. J. J. Mayrhofer, D. Strmcnik, B. B. Blizanac, V. Stamenkovic, M. Arenz and N. M. Markovic, Electrochim. Acta, 2008, 53, 3181.

38 T. Inasaki and S. Kobayashi, Electrochim. Acta, 2009, 54, 4893.

39 F. H. B. Lima, J. Zhang, M. H. Shao, K. Sasaki, M. B. Vukmirovic, E. A. Ticianelli and R. R. Adzic, J. Phys. Chem. C, 2007, 111, 404.

40 J. Zhang, M. B. Vukmirovic, Y. Xu, M. Mavrikakis and R. R. Adzic, Angew. Chem., Int. Ed., 2005, 44, 2132.

41 R. R. Adzic, J. Zhang, K. Sasaki, M. B. Vukmirovic, M. Shao, J. X. Wang, A. U. Nilekar, M. Mavrikakis, J. A. Valerio and F. Uribe, Top. Catal., 2007, 46, 249. 